\title{
SERVIÇOS PÚBLICOS NAS RELAÇÕES DE CONSUMO
}

\author{
ALVARO LAZZARINI* \\ 1. Considerações Gerais. 2. Órgão Públicos. 2.1 Execução dos Serviços \\ Públicos. 3. Serviços adequados, eficientes, seguros e, quando essenciais, \\ contínuos.
}

\section{Considerações Gerais}

O artigo 22 do Código de Defesa do Consumidor, Lei $\mathrm{n}^{\mathrm{Q}} 8.078$, de 11 de setembro de 1990, é expresso, no caput e no parágrafo único, em obrigar que os órgãos públicos, por si ou suas empresas, concessionárias e permissionárias, ou sob qualquer outra forma de empreendimento, forneçam serviços adequados, eficientes, seguros e, quanto aos essenciais, contínuos, certo que, na hipótese de descumprimento, total ou parcial, dessas obrigações, serão as pessoas jurídicas compelidas a cumpri-las e a reparar os danos causados, na forma prevista o mesmo Código.

Referida norma de natureza cogente, é bem verdade, limita-se a prever a responsabilidade civil das pessoas jurídicas que indica, pelos danos que causarem, no que está de acordo com o princípio da impessoalidade previsto no artigo 37, caput, da Constituição da República, bem como conforme a previsão do mesmo artigo, agora, no seu parágrafo único, que cuida da responsabilidade civil objetiva das pessoas jurídicas de direito público e das direito privado prestadoras de serviços públicos por danos que seus agentes, nessa qualidade, causarem a terceiros.

A Administração Pública, em qualquer dos Poderes do Estado, porém, por uma questão cultural, não se apercebeu da vigência cogente da norma do artigo 22 do Código de Defesa do Consumidor, e, bem por isso, nem sempre os serviços prestados pelos órgãos públicos, por si ou pelas pessoas jurídicas de direito privado prestadoras de serviços públicos são adequados, eficientes, seguros e, quanto aos essenciais, contínuos.

* Desembargador do Tribunal de Justiça do Estado de São Paulo, Professor de Direito Administrativo, Sócio Colaborador do Instituto dos Advogados de São Paulo e Membro do Conselho Deliberativo da Associação Brasileira dos Constitucionalistas - Instituto Pimenta Bueno.

R. Dir. Adm.,

Rio de Janeiro, 215: 143-150, jan./mar. 1999 
Só se aperceberá da necessidade de fornecer serviços públicos adequados, eficientes. seguros e contínuos no exato momento que seus agentes públicos, também, se aperceberem que, em ação regressiva, serão obrigados a reembolsar aquilo que as pessoas jurídicas, que integram, tiveram de pagar ao ofendido pelo descumprimento das obrigações previstas no citado artigo 22 do Código de Defesa do Consumidor em razão de ação ou omissão do próprio agente público, sendo essa responsabilidade subjetiva.

$\mathrm{O}$ agente público, igualmente, de tal se aperceberá se for observado pelo Ministério Público, na sua função institucional de promover, privativamente, ação penal pública (artigo 129, inciso I, da Constituição da República), no caso, pela hipótese do artigo 75 do Código de Defesa do Consumidor, que determina que seja responsabilizado criminalmente quem, na medida de sua culpabilidade e de qualquer forma, concorrer para os crimes referidos no aludido Código, não se descartando a responsabilização por "improbidade administrativa" a teor do artigo 11, combinado com o artigo 22 da Lei de Improbidade Administrativa, Lei $n^{9} 8.429$, de 2 de junho de 1992, e tudo isso sem prejuízo da responsabilidade administrativa disciplinar em que incida o agente pela violação do dever funcional de operacionalizar serviços públicos adequados, eficientes, seguros e contínuos, em qualquer hipótese, pois, todo serviço público se mostra essencial à coletividade administrada.

A previsão do artigo $22 \mathrm{em}$ exame, a bem da verdade, fez a adequação de conhecidos princípios jurídicos de Direito Administrativo às relações de consumo, razão de, no exercício da cidadania, qualquer pessoa, física ou jurídica, tem o inalienável direito de, pelas vias processuais cabíveis, exigir do Poder Judiciário, que não age de ofício, as providências que a hipótese requeira, mesmo porque nem a lei pode excluir da apreciação do Poder Judiciário lesão ou ameaça a direito (artigo $5^{\mathfrak{Q}}$, inciso XXXV, da Constituição da República).

\section{2. Órgãos Públicos}

O artigo 22 do Código de Defesa do Consumidor ao certo se refere a órgãos que integram pessoas jurídicas de direito público interno (órgãos públicos), como também aqueles que integram pessoas jurídicas de direito privado (órgãos privados) e, eventualmente, a pessoas físicas que possam ter alguma delegação para execução indireta de serviços públicos. ${ }^{1}$

Interessa examinar no tocante às pessoas jurídicas, cujos órgãos são aqueles que estejam fixados na sua estrutura organizacional, que decorra do seu ato constitutivo, seja o seu contrato ou estatuto social se pessoa jurídica de direito privado ou, então, da sua lei fundamental se pessoa jurídica de direito público interno.

1 O Estatuto da Concessão e Permissão de Serviços e Obras Públicas, Lei n̊ 8.987, de 13 de fevereiro de 1995 , no seu artigo $2^{2}$, inciso II, restringiu a delegação de concessão de serviço público só à pessoa jurídica ou consórcio de empresa, de modo que pessoa física só pode ter delegação de permissão de serviço público a teor do mesmo artigo, inciso IV. 
A pessoa jurídica, em qualquer dessas hipóteses, não tem como praticar atos, manifestando a sua vontade, a não ser através de pessoas físicas. Elas dependem, portanto, de pessoas físicas para manifestar vontade.

Quando uma pessoa jurídica, assim, manifesta a sua vontade, na verdade é a vontade da pessoa física que, do seu plano físico, converte-se em órgão volutivo da coletividade, agora no plano jurídico, conforme Jellinek, que sustentou a "Teoria do Órgão" exposta por Otto Gierke e transcrita por Mário Masagão. ${ }^{2}$

Essa vontade da pessoa física, porém, só pode ser manifestada dentro de uma esfera de competência funcional, pois, as suas atribuições são limitadas aos moldes previstos no ato constitutivo da pessoa jurídica, certo que em se tratando de pessoa jurídica de direito público nos estritos termos do que a norma constitucional ou a norma infraconstitucional, a lei, lhe delimitaram, uma vez que se sujeita ao principio da legalidade estrita, pelo que só pode fazer ou deixar de fazer algo conforme expressa previsão legal.

Não sobra, portanto, à pessoa física que atue em nome do Estado, exercendo alguma função ou cargo público, vontade própria, porque, a vontade sua está jungida à vontade da lei, que lhe dita as ordens e instruções de como individualizá-la diante de um caso concreto.

A sua vontade, assim, deve limitar-se a cumprir e fazer cumprir a lei, na esfera de sua competência que vincula a sua vontade.

Essa corrente da "Teoria do Órgão", conhecida como corrente técnica, "sustenta que o órgão é constituído por dois elementos: de um lado, o funcionário ou funcionários, que representam a ação, a vontade; e, de outro lado, o complexo das atribuições individualizadas pela lei, ou seja, uma esfera de competência. Esta é a doutrina atualmente aceita." 3

É de Celso Antonio Bandeira de Mello a afirmação de poder-se "conceituar os órgãos como 'unidades abstratas que sintetizam os vários círculos de atribuições do Estado.' Estes devem ser expressados pelos agentes investidos dos correspondentes poderes funcionais, a fim de exprimir na qualidade de titulares deles, a vontade estatal." 4

Daí insistir Hely Lopes Meirelles que "Órgãos públicos são centros de competência instituídos para o desempenho de funções estatais, através de seus agentes, cuja atuação é imputada à pessoa jurídica a que pertencem." 5

Em resumo, todo órgão, público ou privado, implica na existência de uma pessoa física que, como agente, atua para, nos limites do que lhe foi individualizado em ordens ou instruções pertinentes à sua natureza abstrata, manifestar a vontade da pessoa jurídica a que pertence.

2 MASAGÃo, Mário. Curso de Direito Administrativo, 5ª ed., 1974, Editora Revista dos Tribunais, São Paulo, n. 113-114, p. 46; idem L. MEIRELLES, Hely. Direito Administrativo Brasileiro, $21^{\mathbf{a}}$ ed., 1996, Malheiros Editores, Sāo Paulo, nota 20, p. 63.

3 MASAGÃO, Mário. Obra e ed. cits., n² 121, p. 48.

4 BANDEIRA DE MELLO, Celso Antonio. Apontamentos sobre os agentes e órgāos públicos, $1^{\mathbf{a}} \mathrm{ed}$., 3a tiragem, 1981, Editor Revista dos Tribunais, São Paulo, p. 69.

5 L. MEIRELLES, Hely. Obra e ed. cits., p. 63 
Será público o órgão se de direito público for a pessoa jurídica, devendo o seu agente, pessoa física, seguir as ordens e instruções que lhe forem ditadas pelas leis e regulamentos administrativos.

Na hipótese do artigo 22 do Código de Defesa do Consumidor o órgão público, previsto em lei e integrado por um agente público, pessoa física que atua em nome do Estado, dentro da esfera de sua competência legal, deverá fornecer serviços públicos adequados, eficientes, seguros e contínuos, atento, em outras palavras, aos princípios jurídicos que informam o moderno Direito Administrativo, sob as penas da lei.

Mister, porém, se torna deixar certo que tal afirmação diz respeito ao só órgão competente para prestá-los, lembrando-se, a propósito, a saudável lição de Caio Tácito no sentido de que "A primeira condição de legalidade é a competência do agente. Não há, em direito administrativo, competência geral ou universal: a lei preceitua, em relação a cada função pública, a forma e o momento do exercício das atribuições do cargo. Não é competente quem quer, mas quem pode, segundo a norma de direito. A competência é, sempre, um elemento vinculado, objetivamente fixado pelo legislador." 6

Não pretenda, bem por isso, o consumidor buscar serviço público adequado, eficiente, seguro e contínuo em órgão público juridicamente incompetente para prestá-lo por não estar na esfera de suas atribuições. Não pretenda, de outro lado, o agente público, por mais competente que seja tecnicamente para fazê-lo, prestar serviço público que não está na sua esfera de competência legal, pois, se assim o fizer estará se havendo com abuso de poder, por desvio ou excesso de poder, sujeitando-se, igualmente, às sanções da lei.

\subsection{Execução dos Serviços Públicos}

O Estado, através de seus órgãos públicos próprios, tem o dever de prestação dos serviços públicos que lhe são inerentes, em especial aqueles voltados à sua atividade jurídica de declarar o direito (atividade legislativa), de distribuir a justiça (atividade judicial), de preservação da ordem pública (atividade policial) e de defesa da nação contra o inimigo externo (atividade das forças armadas).

Mas, como prelecionado por José Joaquim Cardozo de Mello Neto, "O Estado exerce ao lado da sua actividade juridica, uma actividade social. Ao Estado é impossível circunscrever a sua esphera de acção à actividade jurídica. Aliás, a concepção individualista do Estado não teve jamais correspondente na realidade objectiva: não se limitando à tutela do direito, o Estado agiu sempre no sentido de promover o bem-estar e a prosperidade sociaes. A interferência do Estado, para ser

6 TÁCITO. Caio. O Abuso de Poder Administrativo no Brasil (Conceito e Remédios), 1959, Departamento Administrativo do Serviço Público e Instituto Brasileiro de Ciências Administrativas, Rio de Janeiro, p. 27. 
legítima, precisa basear-se no interesse commum. Subordinada a este critério, ella facilita o exercício da actividade jurídica." 7

Assim, a busca do desenvolvimento da população e o seu equilíbrio com a área territorial, a solução dos problemas com a educação e instrução pública, bem como com a saúde pública e, ainda, com a ordem econômica, setores da denominada ação social em sentido estrito que, em princípio, só devem ser fornecidos pelos órgãos públicos do Estado, quando a iniciativa privada não atue de modo a atender aos interesses da coletividade administrada no caso concreto.

Bem por isso, a exploração direta de atividade econômica pelo Estado continua autorizada pela Constituição da República de 1988, desde que, ressalvados os casos nela previstos, seja necessária aos imperativos da segurança nacional ou a relevante interesse coletivo, conforme definidos em lei (artigo 173, caput).

Daí por que o Estado não está impedido de descentralizar suas amplas e complexas atividades "de prestação de serviços públicos e de utilidade pública, que se outorgam às autarquias e entidades paraestatais, ou se delegam a concessionários, permissionários e autorizatários, ou se executam por acordos sob a modalidade de convênios e consórcios administrativos." 8

Cuida-se da execução indireta do serviço, em que "o responsável pela sua prestação aos usuários comete a terceiros para realizá-los nas condições regulamentares. Serviço próprio ou delegado, feito por outrem, é execução indireta. Portanto, quer a Administração direta, quer a Administração indireta (autarquias, empresas públicas e sociedades de economia mista), como, também, os entes de cooperação (fundações, serviços sociais autônomos etc.), ou as empresas privadas e particulares que receberem serviços públicos ou de utilidade pública para prestar aos destinatários, podem, em certos casos, executar indiretamente o serviço, contratando-o (não delegando) com terceiros. A possibilidade de execução indireta depende, entretanto, da natureza do serviço, pois alguns existem que não admitem substituição do executor, como. p. ex., os de polícia, e para outros a própria outorga ou delegação proíbe o transpasse da execução." 9

Há, ao certo, um verdadeiro sistema de parceria entre os setores públicos $e$ privado na execução de serviços através de concessões, permissões, terceirizações e outros regimes que só mais recentemente começou a ser estudado pelos publicistas, como o atesta Diogo de Figueiredo Moreira Neto, ao enfatizar que "Cogita-se, aqui, de uma articulação de instrumentos de parceria entre os setores públicos e privado, o que pressupõe que se tenha definido a significação que se deve dar a este termo no Direito Público, uma vez que sua existência está registrada no Direito Privado. Com efeito - continua - , a palavra parceria, do latim partiarius, participante, vem sendo empregada tradicionalmente em direito para designar uma forma sui generis de sociedade em que não se dá a composição de um capital social nem a instituição

7 CARDozo de MEllo NETO, José Joaquim. A Aç̧āo Social do Estado, 1917, Secção de Obras do "O Estado de S. Paulo", São Paulo, p. 63.

8 L. MEIRELLES, Hely. Obra e ed. cits., p. 309.

9 L. MEIRELLES, Hely. Obra e ed. cits., p. 308. 
de uma nova pessoa, mas, apenas, uma relação negocial, em que uma das partes assume obrigações determinadas com vistas a participar de lucros alcançados. Como se observa, não obstante possam existir outras modalidades de colaboração, não necessariamente econômicas, o vocábulo parceria carrega consigo o sentido de lucro. A transposição dessa expressão da órbita privada, onde teve origem e desenvolvimento teorético, para a órbita pública, onde chega por extensão, trazida da linguagem de economista, técnicos em administração e jornalistas, não implica, todavia, em expandir-lhe o significado além do econômico, ou seja: como uma modalidade de colaboração entre o setor privado e o setor público em que entidades não estatais participem em atividades estatais de índole econômica auferindo lucros em sua execução. Trata-se, portanto, de um instituto de colaboração, tal como conhecido na doutrina jus-administrativista de longa data, ao lado do instituto afim da cooperação, que se negocia entre entidades estatais, daí ser até mesmo discutível a necessidade de transplantar o termo parceria para rebatizar a colaboração econômica (...) entre entidades públicas e privadas." 10

Como destinatário final dos serviços prestados pelo Estado, por si ou suas empresas, concessionárias, permissionárias ou sob qualquer outra forma de fornecimento desses serviços, sujeito que está ao pagamento de tributos, o consumidor, pessoa física ou jurídica, está ao abrigo do Código de Defesa do Consumidor, Lei $\mathrm{n}^{\text {o }} 8.078$, de 11 de setembro de 1990, cujas normas de ordem pública e interesse social foram impostas nos termos dos artigos $5^{\circ}$, inciso XXXII, e 170 , inciso $\mathrm{V}$, da Constituição da República e artigo 48 de suas Disposições Transitórias.

Nesse sentido, justamente, está o artigo 22 do Código de Defesa do Consumidor, como de início destacado, restando, agora, examinar a temática dos serviços fonececidos pelos órgãos públicos, por si ou pelas entidades a que alude a mesma norma do artigo 22 e que devem ser "serviços adequados, eficientes, seguros e, quanto aos essenciais, contínuos".

\section{Serviços adequados, eficientes, seguros e, quando essenciais, contínuos}

Observa Hely Lopes Meirelles que “Os direitos do usuário são, hoje, reconhecidos em qualquer serviço público ou de utilidade pública como fundamento para a exigibilidade de sua prestação nas condições regulamentares e em igualdade com os demais utentes. São direitos cívicos, de conteúdo positivo, consistentes no poder de exigir da Administração ou de seu delegado o serviço que um ou outro se obrigou a prestar individualmente aos usuários. São direitos públicos subjetivos de exercício pessoal quando se tratar de serviço uti singuli e o usuário estiver na área de sua

10 MOREIRA NETO, Diogo de Figueiredo. O Sistema da Parceria entre os Setores Público e Privado - Execução de Serviços através de Concessões, Permissões, Terceirizaçōes e outros Regimes Aplicação Adequada desses Institutos. Palestra proferida no $4^{\circ}$ Seminário Nacional de Direito Administrativo, realizado em São Paulo-SP, novembro de 1996, promovido pela Editora NDJ — Nova Dimensão Jurídica, in "Boletim de Direito Administrativo", Ano XIII, n. 2, fevereiro de 1997, Editora NDJ Ltda., São Paulo, p. 75-81. 
prestação. Tais direitos rendem ensejo às ações correspondentes, inclusive mandado de segurança, conforme seja a prestação a exigir ou a lesão a reparar judicialmente" ", certo que tais serviços, ainda, conforme o saudoso publicista sujeitam-se há "cinco princípios que a Administração deve ter sempre presentes, para exigi-los de quem os preste: o princípio da permanência impõe continuidade no serviço; o da generalidade impõe serviço igual para todos; o da eficiência exige atualização do serviço; o da modicidade exige tarifas razoáveis; e o da cortezia traduz-se em bom tratamento para com o público. Faltando qualquer desses requisitos em um serviço público ou de utilidade pública, é dever da Administração intervir para restabelecer seu regular funcionamento ou retomar sua prestação." 12

Em linhas gerais a norma do artigo 22 do Código de Defesa do Consumidor adotou esses princípios, como requisitos nas relações de consumo envolvendo órgãos públicos em geral, por si ou suas empresas, concessionárias, permissionárias ou qualquer outra forma de empreendimento ao dispor que o fornecimento de serviços sejam adequados, eficientes, seguros e, quanto aos essenciais, contínuos.

Mais recente, a Lei no 8.987, de 13 de fevereiro de 1995, Estatuto da Concessão e Permissão de Serviços e Obras Públicas, reiterou a observância da boa doutrina e do artigo 22 do Código de Defesa do Consumidor, Lei $\mathrm{n}^{\circ} 8.078$, de 11 de setembro de 1990, provendo sobre "Serviço Adequado", no seu Capítulo II, o artigo 60, com o seu caput e $\S \S 1^{9}$ a $3^{2}$, que dispõe que toda concessão ou permissão pressupõe a prestação de serviço adequado ao pleno atendimento dos usuários, conforme as normas pertinentes que a lei ou o respectivo contrato estabelecem, conceituando, ao depois, que "Serviço adequado é o que satisfaz as condições de regularidade, continuidade, eficiência, segurança, atualidade, generalidade, cortezia na sua pres-

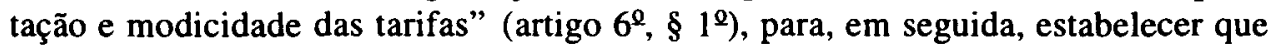
"A atualidade compreende a modernidade das técnicas, do equipamento e das instalações e a sua conservação, bem como a melhoria de expansão do serviço" (artigo $6^{0}, \S 2^{0}$ ).

O artigo $6^{0}, \S 3^{9}$, do aludido Estatuto da Concessão e Permissão, igualmente, deixo certo não se caracterizar como descontinuidade do serviço a sua interrupção em situação de emergências ou após prévio aviso, quando motivada por razões de ordem técnica ou de segurança das instalações, bem como por inadimplemento do usuário, considerado o interesse da coletividade.

Daí por que torna útil sempre conciliar a previsão do artigo 22 do Código de Defesa do Consumidor com os conceitos expostos no artigo $6^{0}$ do Estatuto da Concessão e Permissão, que lhe é posterior.

Quanto aos serviços ou atividades essenciais, José Cretella Júnior observa que "A essencialidade do trabalho é que deve ser levada em conta pelo legislador. Pode haver serviço público 'não essencial' e serviço público 'essencial', o mesmo ocorrendo com o serviço privado, ou atividade privada, classificada em essencial ou não-essencial. 'A essencialidade da atividade é essencial' é proposição de nítido

11 L. MEIRELLES, Hely. Obra e ed. cits., p. 301.

12 L. MEIRELLES, Hely. Obra e ed. cits., p. 301. 
truísmo (cf. Pontes de Miranda, Comentários, $3^{\underline{a}}$ ed., Rio de Janeiro, Ed. Forense, 1987, v. VI, p. 54), porque é da natureza da coisa a existência do próprio atributo. 'Essencialidade' envolve juízo de valor e, por isso, não se discute no plano lógico, mas apenas no jurídico. 'Serviços ou atividades essenciais' são aqueles que a regra jurídica ordinária define como tal. E a lei tem de ser federal." 13

$\mathrm{O}$ artigo 22 do Código de Defesa do Consumidor exige o cumprimento do princípio da continuidade só quando os serviços fornecidos sejam essenciais e, como focalizado, a essencialidade de um serviço há de estar previsto em lei federal, hipótese prevista, expressamente, no artigo $6^{\circ}$ do Estatuto da Concessão e permissão para os serviços concedidos ou permitidos, de modo que a concessionária ou permissionária só poderá interrompê-lo em situação de emergência ou após prévio aviso, quando motivada por razões de ordem técnica ou de segurança das instalações e por inadimplemento do consumidor, como usuário, considerado sempre o interesse da coletividade (artigo $2^{\mathfrak{Q}}, \S 3^{\mathrm{Q}}$, incisos I e II, do Estatuto da Concessão e Permissão).

O princípio da continuidade, como princípio jurídico que é, informa toda atividade da Administração Pública que "devem ser ininterruptas, para que o atendimento do interesse da coletividada não seja prejudicado", como bem lembrado por Odete Medauar. ${ }^{14}$

O princípio da continuidade do serviço público, atesta Maria Sylvia Zanella Di Pietro ${ }^{15}$, faz entender que "o serviço público, sendo a forma pela qual o Estado desempenha funções essenciais ou necessárias à coletividade, não pode parar", com as suas repercussões no direito de greve nos serviços públicos, a ser exercido "nos termos e nos limites definidos em lei complementar" (artigo 37, inciso XII, da Constituição da República), além de outras, por exemplo, "a impossibilidade, para quem contrata com a Administração, de invocar a exceptio non adimpleti contractus nos contratos que tenham por objeto a execução de serviço público; a faculdade que se reconhece à Administração de utilizar os equipamentos e instalações da empresa que com ela contrata, para assegurar a continuidade do serviço; com o mesmo objetivo, a possibilidade de encampação da concessão de serviço público." 16

Daí ser bem ampla, como focalizado, a abrangência da defesa do consumidor em relação aos serviços fornecidos pelos órgãos públicos e demais entidades mencionadas no artigo 22 do Código de Defesa do Consumidor.

Basta que ele, como usuário desses serviços, para o pleno exercício de sua cidadania, utilize dos mecanismos que o Código de Defesa do Consumidor, no seu artigo $5^{\circ}$, coloca ao seu alcance para a fiel execução de uma verdadeira política nacional das relações de consumo.

13 CRETELla JÚNIOR, José. Comentários à Constituição Brasileira de 1988, $1^{\text {a }}$ ed., 1989, Forense Universitária, Rio de Janeiro, v. II, $\mathrm{n}^{2}$ 198. p. 1.063.

14 MEDAUAR, Odete. Direito Administrativo Moderno, $1^{\text {a }}$ ed., 1996. Editora Revista dos Tribunais, São Paulo, p. 146.

15 DI PIETRO, Maria Sylvia Zanella. Direito Administrativo, $5^{\mathbf{a}}$ ed.. 1994. Editora Atlas. São Paulo, p. 67.

16 DI PIETRO, Maria Sylvia Zanella. Obra, ed. e p. cits. 